\title{
Author Correction: Pathological inflammation in patients with COVID-19: a key role for monocytes and macrophages
}

\author{
Miriam Merad and Jerome C. Martin (iD
}

Nature Reviews Immunology (2020) https://doi.org/10.1038/s41577-020-0331-4 Published online 06 May 2020

In the originally published article, the imprecise wording of a sentence implied that IL- 6 blockade had been approved by the FDA for treatment of COVID-19. This has now been corrected in the HTML and PDF versions of the article to clarify that the FDA had, at the time of writing, only approved trials of IL-6 blockade in patients with COVID-19.

https://doi.org/10.1038/s41577-020-0353-y I Published online 2 June 2020

(C) Springer Nature Limited 2020

\section{Author Correction: COVID-19: the vasculature unleashed}

Laure-Anne Teuwen, Vincent Geldhof, Alessandra Pasut and Peter Carmeliet (D)

Nature Reviews Immunology (2020) https://doi.org/10.1038/s41577-020-0343-0

Published online 21 May 2020

In the originally published article, the following affiliation for Peter Carmeliet was missing: State Key Laboratory of Ophthalmology, Zhongshan Ophthalmic Center, Sun Yat-Sen University, Guangzhou, Guangdong, P.R. China. Also, the sentence "Moreover, ECs seem to be gatekeepers of this immune response, as inhibition of the sphingosine 1 phosphate receptor 1 (S1PR1) in pulmonary ECs dampens the cytokine storm in influenza infection" has been corrected to "Moreover, ECs seem to be gatekeepers of this immune response, as modulation of the sphingosine 1 phosphate receptor 1 (S1PR1) in pulmonary ECs dampens the cytokine storm in influenza infection".

https://doi.org/10.1038/s41577-020-0356-8 I Published online 4 June 2020

(c) Springer Nature Limited 2020

\section{Author Correction: Complement as a target in COVID-19?}

Antonio M. Risitano, Dimitrios C. Mastellos (ID, Markus Huber-Lang, Despina Yancopoulou, Cecilia Garlanda, Fabio Ciceri and John D. Lambris (D)

Nature Reviews Immunology (2020) https://doi.org/10.1038/s41577-020-0320-7 Published online 23 April 2020

In the originally published article, Cecilia Garlanda's affiliations were incompletely listed as ${ }^{5}$ Humanitas Clinical and Research Center, Milan, Italy and ${ }^{6}$ Humanitas University, Milan, Italy.

These have now been corrected to ${ }^{5} \mathrm{Humanitas}$ Clinical and Research Center, IRCCS, Rozzano, Milan, Italy and ${ }^{6} \mathrm{Humanitas}$ University,

Pieve Emanuele, Milan, Italy.

https://doi.org/10.1038/s41577-020-0366-6 I Published online 12 June 2020

(c) Springer Nature Limited 2020

\section{Publisher Correction: Delphine Parrott, a pioneer of T cell biology}

\section{Allan M. Mowat}

Nature Reviews Immunology (2020) https://www.nature.com/articles/s41577-020-0292-7 Published online 28th February 2020

The title of the publication misspelled 'Parrott' as 'Parrot'. This has been corrected.

https://doi.org/10.1038/s41577-020-0329-y I Published online 1 May 2020

(C) Springer Nature Limited 2020

\section{Publisher Correction: Risk factors for death from COVID-19}

\section{Myvizhi Esai Selvan}

Nature Reviews Immunology (2020) https://doi.org/10.1038/s41577-020-0351-0 Published online 27 May 2020

The originally published version of this article cited the author's surname incorrectly. The author's surname should be cited as Esai Selvan. This has now been corrected online.

https://doi.org/10.1038/s41577-020-0371-9 I Published online 12 June 2020

(c) Springer Nature Limited 2020 